\title{
Discussion on the Educational Status and Development of Martial Art and Traditional Physical Majors
}

\author{
Wang Haibo \\ College of Sports Science,Jishou University, \\ Jishou, China \\ e-mail:2862923557@qq.com
}

\begin{abstract}
Traditional sport belongs to our brilliant culture. Nowadays, people have had an increasingly complete knowledge about traditional sports; and meanwhile majors of traditional sports have been constantly set up in colleges and universities, aiming to achieve a sound development of traditional physical course by cultivating professional talents. In the paper, relative concepts as well as educational construction process of national martial art and traditional physical majors are reviewed so as to propose corresponding development measures addressing current problems to further promote the construction of traditional national sports education.
\end{abstract}

Keywords-martial art; traditional sports; educational status; development measures

With the constant perfection of national educational system and discipline construction, majors of martial art and traditional sport have been constantly set up in more and more colleges and universities so as to promote the development of traditional sports. However, affected by various factors, there are still certain problems existing in current traditional sports. Therefore, colleges and universities should strengthen their professional construction to promote a sound and healthy development of martial art and traditional sport continuously.

\section{RELATED CONCEPTS OF MARTIAL ART AND TRADITIONAL SPORTS}

National traditional sports refer to those sports events which are produced and accumulated during social development and people's life practice in modern times and are still popular today. National traditional sport is an important component of traditional culture, so it has deep cultural deposit and excellent inheritance. The external scope of traditional sport mainly includes the following parts. During the inheritance and development of nationality, some nationalities have their own unique sports with comparative personalities and limited inheritance; some sports events produced in ancient China but still remain stereotypical forms with significance effect; some sports events have been widely accepted in the world with wide social communication, including martial art. At present, in order to better inherit and develop martial art and traditional sport, most colleges and universities have set majors for martial art and traditional sports so as to cultivate high-quality talents suitable for social construction and development with basic knowledge and skills, which is also good for sports science and research as well as physical education.

\section{HistoricAl STUDY ON PROFESSIONAL EDUCATION OF MARTIAL ART AND TRADITIONAL SPORTS}

Since the late 1980 s to the early 1990 s, sports colleges have gradually paid attention to martial education with establishment of martial art major. Since then, martial art had been formally included to educational system with production of a group of professional martial talents with bachelor degree. In 1982, the first master degree for martial theory and method was established in Shanghai University of Sport nationwide, which had been widely approved since then. In 1996, doctor degree of martial art was set in Shanghai University of Sport, indicating the highest level of martial teaching in our country. As traditional sports have obtained more attention from public, they have been set as educational majors in undergraduate period by the Ministry of Education in 1998, which belongs to a secondary discipline of physical science. Establishment of this discipline makes the teaching of traditional sports more professional, which creates larger space for the development of traditional sports. In recent years, educational course of traditional sports has been rapidly developed in China with a third-layer cultivation system for bachelor, master and doctor degrees. However, in practical society, graduates from this major are faced with difficult employment circumstance due to the lack of complete knowledge and cognition of traditional sports by many enterprises and units. Thus, to solve the problem, major of traditional sports are renamed as martial art and traditional sports by the Ministry of Education.

\section{EDUCATIONAL StATUS OF MARTIAL ART AND TRADITIONAL SPORTS MAJOR}

\section{A. Lack of completeness for its administrative system}

At present, as people are attaching greater importance to the major of martial art and traditional sports, related departments are enhancing the rational administration on traditional sports major, but there are still many problems needing to be solved. As for the management of traditional sports major, government institutes, sports management organizations as well as colleges have different and complicated responsibilities, requiring to be further perfected and standardized. For now, both the 
recruitment and source plan of national traditional sports major are formulated uniformly by the State General Administration of Sports, and standard for the source students is also formulated by related examination units entrusted by the State General Administration of Sports; while Ministry of Education is only responsible for corresponding management on employment and results evaluation. Such kind of management model will lead to a more difficult and complicated management among different organizations, which is not good for rational employment of human and social resources with ineffective result. Meanwhile, local governments also have difficulty in managing traditional national sports. At present, traditional sports in local colleges and universities are not only restricted by local government, but they are also administrated by the State Bureau of Education and State General Administration of Sports. For this reason, the complex administration structure is difficult to be optimized, and it will affect the unified and coordinated management of traditional sports, which is bad for the professional development of those colleges.

\section{B. Lack of Professional and Instructive Theories}

In recent years, the course of national traditional sports has been developed rapidly but with imperfect professional theoretical system, project setting, content provision as well as evaluation indicators and systematic theoretical knowledge for its short history. Development of modern society has gradually affected the transition of social structure, making the reform of national traditional sports urgent. Therefore, some relative units or colleges should study problems existing in the reform of traditional sports systematically to perfect it. In modern society, China is short of theoretical studies on the goal setting for the major of traditional sports, so the teaching tasks and teaching contents cannot be differentiated without true mastery of professional development orientation and development goals. At present, although the recruitment in various colleges of sports has been enlarged, graduates of different majors from these schools are faced with difficult employment since their majors are of great similarities.

\section{The educational goals lag behind the development of modern society}

The educational goal is the final purpose of school teaching, which mainly refers to the teaching aim and educational orientation of traditional sports. It will meet the corresponding teaching standard and teaching size eventually by training professional talents specially. At present, graduates from the major of martial art and traditional sports have a comparatively wide choices, but most of them are up to the safeguard and security job. Therefore, current education of traditional sports should not be restricted to basic physical training as well as skill training. Colleges should cultivate students into all-roundway excellent talents with the development of modern society. However, during the teaching of traditional sports majors like martial art in colleges and universities, students haven't been developed in a comprehensive way for multi-skilled teaching, which is not beneficial for them to find jobs.

The curriculum settings of martial art and traditional physical majors in China now include public compulsory courses, limited courses, random optional courses, special and secondary courses with an imperfect curriculum system. Besides, colleges have made corresponding adjustment for their own courses according to their own teaching level and teaching requirements, which is good for promoting their students' professional skills and qualities, but it has little effect in developing students' comprehensive qualities. During the development of modern society, higher and higher requirements have been raised for talents. Therefore, during the cultivation of modern talents, not only professional skills and literacy should be conducted, but teaching should also be conducted to promote students' comprehensive qualities. Moreover, in the curriculum settings of different colleges, there is much knowledge in different subjects, but there is little crossed knowledge with little effective links among different disciplines. The repeated curriculum setting as well as compulsory courses setting also affects the promotion of modern students' comprehensive qualities.

\section{EDUCATIONS ON MAJORS OF MARTIAL ART AND TRADITIONAL SPORTS}

\section{A. A.To innovate and perfect teaching management system}

During the recruitment and school study of students, government institute, State Administration of Sports as well as schools should make adjustments for their disordered functions and rights with strict division of their administration scopes. As for the State Administration of Sports, its main function is to manage professional education, while colleges of martial art as well as various colleges of sports should be administrated by local governments uniformly. The division of the administrative rights above can clarify and perfect the administration chain. It is not only good to school teaching plans, but it also helps to promote resource allocation and smart management. At present, colleges of sports in China are mainly administrated by the State Administration of Sports, which combines sports and teaching management together. Thus, they should fulfill their functions strictly by their rights to formulate professional cultivation plans for students in colleges of martial art and colleges of sports. Meanwhile, students can be delivered to different schools for further education according to their learning conditions. For example, outstanding students from the major of martial art should be arranged for systematic study actively to promote better development.

During the graduation, Ministry of Education should formulate corresponding preferential employment policies for graduates according to their types and characteristics. As for graduates who choose to work in rural and remote areas, Ministry of Education should formulate special preferential policies for them. Entrepreneurial factors play an important role in graduates' employment, so graduates could be encouraged to starting a business with 
preferential and awarding policies so as to achieve effective employment.

\section{B. Pay more attention to scientific research to perfect the construction of professional instructive theories}

Addressing current incomplete professional instructive theories, related departments and colleges should strengthen scientific research with constant exploration on the professional theoretical knowledge contained in martial art and traditional sports so as to constantly perfect the construction of theories. In colleges of sports, teachers' abilities of scientific research should be promoted with frontier knowledge since they face the students directly during the teaching process. Therefore, the most advanced and the most instructive theories shall be employed during teaching activity to achieve efficient teaching. Scientific research is the the convenient way to acquire the most advanced and perfect professional theories. Teachers should place emphasis on perfecting their own professional knowledge during scientific research with innovative thoughts.

\section{Pay attention to classified construction}

During the process of classified construction, colleges of sports should value their own resources and competitive advantages with emphasis on the construction and openness of school sports competition. Meanwhile, development and openness of competitive sports should be regarded as main content of their own construction with cultivation of high-quality and high-level sports teams. Thus, a large group of excellent athletes and coaches can be cultivated. By this way, the popularity of the college itself can also be promoted with a sound common development between the school and the students.

China has lots of provinces with relatively different cultures. It is impossible for all the colleges of sports nationwide to conduct construction and development for traditional sports events. Therefore, according to this social status quo, different plans and studies should be made for traditional sports events by their own development situations and local characteristic. Some events can be selected with more emphasis so as to form unique teaching characteristic. For example, the Northern colleges of sports can pay more attention to wrestling and archery; while northern schools can extend more attention to water events such as Dragon Boat competition. Besides, different schools of martial arts such as Henan Shaolin Boxing Association can be established in colleges of sports with regular discussion and communication so as to constantly realize the characteristic teaching to promote the inheritance and development of brilliant culture.

\section{Give importance to the reform of curriculum and teaching contents}

The setting of curriculum system and teaching contents is the basis of education and teaching. Under the development of modern society, schools should pay attention to the promotion of students' professional skills and comprehensive qualities so as to cultivate students' innovative spirits. As for the curriculum setting of martial art and traditional sports, schools should change the irrational phenomenon by establishing a new teaching mode combined comprehensive talents with professional cultivation together so as to develop creative talents with multiple skills. Thus, main teaching courses should be highlighted during curriculum setting with unique teaching characteristic to avoid similarity. Besides, the proportion of optional courses should be increased to develop students' individuality so that students can realize cross-discipline study based on their professional knowledge. While expanding self knowledge field, their adaptation to society can also be enhanced so as to realize their social values gradually.

\section{CONCLUSION}

To sum up, martial art and traditional sports play an important role in traditional Chinese culture. At present, most Chinese colleges have set majors of martial art and traditional sports, but there are some corresponding problems during the professional management system, study of systematic theories as well as setting of curriculum system. Therefore, a perfect management system should be gradually established to solve those problems with better study of systematic theoretical knowledge and more rational setting of curriculum and educational system, through which Chinese martial art and traditional sports can be developed.

\section{REFERENCE}

[1] Li Yanrong, Ding Chuanwei. Study on the Effect of Curriculum Setting of Martial Art and Traditional Sports on Students' Traditional Cultural and Literary Literacy.[J]. Exercise, 2014,20:7477

[2] Lu Shenghua, Pu Xiafan. Reflections on the Development of Martial Art and Traditional Sports[J]. Asia Pacific Education,2015,02:77+69.

[3] Normal CoLu shenghua, Zhangxu. Study on the Reform of Curriculum Structure for Martial Art and Traditional Sports[J] Journal of Science and Education, 2015,04:24-25

[4] Duan Zicai. Shallow Opinions on Key Problems in the Reform of Martial Art and Traditional Sports in Our Colleges[J]. Journal of Fuyang llege. (Version of Natural Science),2015,02:139-142.

[5] Sunjian. Study on the Talent Cultivation Scheme of Martial Art and Traditional Sports during Undergraduate Study in Colleges of Sports - Taking Guangzhou College of Sports As an Example. [J] Boxing(Martial Science),2015,06:71-73.

[6] Wang Yanqiong, Zhang Shaohua, Tan Zhourong. Investigation and Analysis on the Social Demand for Martial Art and Traditional Sports in Guangxi. [J]. Physical Science, 2014,03:126-127+129.

[7] Ruan Junxian, Yan Donghui. Study on the Crisis and Countermeasures of Martial Art and Traditional Sports in Colleges and Universities[J]. Boxing(Martial Science),2014,02:18-19+26.

[8] He Yanqiang. Study on the Inheritance of Martial Culture During Martial Art Education[D]. Henan University, 2013.

[9] Hu Pingqing. Study on the Functions of Martial Art Education During School Sports[D]. Beijing University of Sports, 2013.

[10] Wu Mingdong, Xin Yanbo. Analysis on the Cultivation of Undergraduate Talents from Martial Art and Traditional Sports Majors[J]. Modern Communication, 2013,06:121-122. 